\title{
OPEN Clinical and immunological allergy assessment in cancer patients
}

\author{
Bruno Gustavo Muzzi Carvalho Carneiro ${ }^{2 凶}$, Andy Petroianu ${ }^{1}$, \\ José Augusto Nogueira Machado ${ }^{3}$, Paula Martins Ferreira dos Anjos ${ }^{3}$, \\ Fabiana Rocha da Silva ${ }^{3}$, Luiz Ronaldo Alberti ${ }^{1}$, Vivian Resende ${ }^{1}$ \& Sofia Candia Barrientos ${ }^{1}$
}

Cancer is associated with immunodeficiency, while allergies result from immune system hyperactivity mediated by cytokines and immunoglobulins. The purpose of this study was to determine the relationship between immune environment of specific cancers and allergies, emphasizing cytokines related to Th1 and Th2 responses associated with IgE. 80 adults were distributed into two groups: control $(n=20)$ and cancer $(n=60)$, distributed in three subgroups $(n=20)$, head and neck, stomach, and prostate cancers. This study compared Th1 (IL-2) and Th2 (IL-4) parameters, anti-inflammatory, pro-inflammatory, or regulatory profile regarding both IgE levels and reported allergies, by means of clinical manifestations and IgE, IL-1 $\beta$, IL-2, IL-4, IL-17, and TGF- $\beta$ serum concentration. Clinically allergies were observed in $50 \%$ of the control group and in $20 \%$ of the cancer group $(p=0.009)$. IL-2 cytokine and TGF- $\beta$ concentrations were higher in the patients with cancer as compared to the control $(p<0.005)$. However, there were IL-4, IL-17, and IL-1 $\beta$ decreases in the patients with cancer $(p<0.05)$. No correlation was observed between the cytokines studied and IgE and clinically proven allergies in both investigated groups. There was an inverse association between cancer and clinical allergy manifestations. In head and neck, stomach, and prostate cancers, an immunosuppressive serum tumor environment was predominant. There was no difference in cytokines related to Th1 and Th2 parameters in relation to IgE. No correlation was found between clinically proved allergies and immunity markers related to the same allergens.

The relation between cancer and allergies may be connected to immunodeficiency and immune surveillance, triggered by each disease ${ }^{1,2}$. Allergic reactions result from the hyperactivity of the (Th)2 auxiliary T-immune response, which activates eosinophils, macrophages, and IgE, by means of IL-4, IL-5, and IL-13 secretion ${ }^{3,4}$. As a result, immune surveillance and cell damage, including malignant cells, are increased ${ }^{1,3,5}$. The IL- 4 increase may direct the antibody production to the IgE isotype, associated with type I hypersensitivity reactions. This allergy process, mediated by IgE, is capable of inhibiting tumor growth due to its cytotoxic effect on cancer cells ${ }^{6-11}$.

According to the immune surveillance concept, the immune system destroys neoplastic cells by means of innate immunity, responsible for immediate detection and destruction of malignant cells ${ }^{12,13}$. In primary or acquired immunodeficiency, as in acquired immunodeficiency syndrome, when immunosuppressants are used, and in elderly patients, there is a predisposition or a higher probability for the occurrence of cancer ${ }^{14-17}$.

Allergo-oncology is a recent multidisciplinary area that studies possible associations between cancer and the Th2 subdivision in the immune system, as well as the relations between tumors and immunity mediated by $\operatorname{IgE}$ and cytokines, to develop immunotherapies for cancer control ${ }^{1,9,18,19}$. Immune mechanisms found in allergic processes indicate new immunotherapy and immunoprophylaxis for this disease $\mathrm{e}^{20}$.

Th1 cells offer protection against intracellular pathogens, contributed to the occurrence of autoimmune and chronic inflammatory diseases, as well as secreting cytokines, such as IL-2, IL- 12 , tumor necrosis factor- $\beta$ (TNF$\beta$ ), and interferon- $\gamma(\operatorname{IFN}-\gamma)^{4,21}$. Other lymphocyte populations have been described in the literature, especially for Th17, which secretes IL-17 associated with autoimmune and extracellular defense diseases, as well as for regulatory $\mathrm{T}$ cells (Treg), associated with immune tolerance, inhibiting effector T cells (Tef), and suppressing destruction by autoantigens ${ }^{4,21-26}$

IL- $1 \beta$ induces a powerful inflammatory response and plays a critical role in the organism's fight against pathogens and harmful agents. However, excessive activation or failure in interrupting the inflammatory response may lead to cell or tissue lesions, resulting in allergy processes, chronic autoimmune inflammatory diseases,

\footnotetext{
${ }^{1}$ Surgery Department of the School of Medicine of the Federal University of Minas Gerais, Belo Horizonte, Brazil. ${ }^{2}$ Service of Oncology of the Alberto Cavalcanti Hospital of the Hospital Foundation of the State of Minas Gerais, Rua Rio Claro 235, ap 401, Belo Horizonte, MG 30411-235, Brazil. ${ }^{3}$ Santa Casa Hospital of Belo Horizonte, Belo Horizonte, Brazil. ${ }^{\varpi}$ email: brunomuzzi@gmail.com
} 


\begin{tabular}{|c|c|c|c|c|}
\hline \multicolumn{2}{|l|}{ Characteristics } & \multicolumn{2}{|c|}{ Groups-N (\%) } & \multirow[b]{2}{*}{$p$} \\
\hline & & Control & Cancer & \\
\hline \multirow{2}{*}{ Gender } & Female & $4(20.0)$ & $8(13.3)$ & \multirow{2}{*}{0.470} \\
\hline & Male & $16(80.0)$ & $52(86.7)$ & \\
\hline \multirow{2}{*}{ Age bracket } & Under 63 years of age & $13(65.0)$ & $27(45.0)$ & \multirow{2}{*}{0.12} \\
\hline & Over 63 years of age & $7(35.0)$ & $33(55.0)$ & \\
\hline \multirow{7}{*}{ Comorbidities } & Absent & $9(45.0)$ & $28(46.7)$ & \multirow{7}{*}{0.897} \\
\hline & Hypertension & $6(30.0)$ & $15(25.0)$ & \\
\hline & Diabetes & $0(0)$ & $3(5.0)$ & \\
\hline & Dyslipidemia & $0(0)$ & $1(1.7)$ & \\
\hline & 2 types of chronic disease & $2(10.0)$ & $7(11.6)$ & \\
\hline & $\geq 3$ types of chronic disease & $2(10.0)$ & $5(8.3)$ & \\
\hline & Migraine & $1(5.0)$ & $1(1.7)$ & \\
\hline \multirow{4}{*}{ Alcoholism } & Absent & $14(70.0)$ & $32(53.3)$ & \multirow{4}{*}{0.01} \\
\hline & Social & $5(25.0)$ & $4(6.7)$ & \\
\hline & Daily & $0(0)$ & $11(18.3)$ & \\
\hline & Former alcoholic & $1(5.0)$ & $13(21.7)$ & \\
\hline \multirow{3}{*}{ Smoking } & Never & $15(75.0)$ & $27(45.0)$ & \multirow{3}{*}{0.020} \\
\hline & Former smoker & $1(5.0)$ & $22(36.7)$ & \\
\hline & Currently smoker & $4(20.0)$ & $11(18.3)$ & \\
\hline \multirow{2}{*}{ Allergy } & Absent & $10(50.0)$ & $48(80.0)$ & \multirow{2}{*}{0.009} \\
\hline & Present & $10(50.0)$ & $12(20.0)$ & \\
\hline \multirow{6}{*}{ Type of allergy } & Absent & $10(50.0)$ & $48(80.0)$ & \multirow{6}{*}{0.005} \\
\hline & Allergic rhinitis & $7(35.0)$ & $9(15.0)$ & \\
\hline & Medication & $2(10.0)$ & $0(0)$ & \\
\hline & Food & $0(0)$ & $3(5.0)$ & \\
\hline & Atopic dermatitis & $1(5.0)$ & $0(0)$ & \\
\hline & Asthma & $0(0)$ & $0(0)$ & \\
\hline
\end{tabular}

Table 1. Characterization of the studied sample. Pearson's chi-squared test. $\mathrm{N}=80$.

and cancer ${ }^{27,28}$. The transforming growth factor- $\beta$ (TGF- $\beta$ ) plays a two-phase role in cancer development and advances: in normal cells, TGF- $\beta$ suppresses tumor genesis. However, once the tumor process has already begun, TGF- $\beta$ creates an immunosuppressive microenvironment by inhibiting IL-2, IL-12, and IFN- $\gamma$. Therefore, local immune tolerance is created, and the TGF- $\beta$ serum concentration is increased, which is frequent in cancer patients $^{29-32}$.

The allergy process is assessed by clinical assessment, skin tests, and total or specific IgE serum levels. However, no direct relation between specific reported allergies nor skin sensitivity to the same allergen has been observed, understanding that a clinical allergy may be accompanied by a negative skin test for the same sensitivity agent ${ }^{33}$. Positive skin tests are observed in people who do not exhibit clinical allergies. In the presence of cancer, a lower rate of reported allergies was observed for the general population, even with a higher incidence of positive skin tests for allergens ${ }^{33}$. The IgE serum measurement (type I hypersensitivity reaction marker) has been used as an objective diagnostic method for allergies. The inverse association between IgE concentration and cancer may be specific to the allergy and tumor types ${ }^{6,20,34,35}$.

The mechanism proposed to explain the association between cancer and allergy is that in allergy a heightened immune response is prevalent, whereas in cancer a hyporesponsive immune response is observed. Thus, in allergic people there would be an increase in production of cytokines related to the Th2 response and increasing the production of IgE against the specific tumor antigen, capable of activating effector cells and destroying tumors ${ }^{36-39}$. However, few studies investigate the measurement of cytokine and other biomarkers in this situation $^{36,37}$. Almost all trials involving cytokines are conducted in animal models ${ }^{19}$, and only two studies with human subjects have been identified ${ }^{38,39}$.

The purpose of this study, which is part of a line of research ${ }^{33,40,41}$, was to determine the relationship between immune environment of specific cancers and allergies, emphasizing cytokines related to Th1 and Th2 responses associated with IgE.

\section{Results}

Demographic data are described in Table 1. There was a predominance of male subjects in the cancer patient group, and the prevalence of alcoholism and smoke was higher in the cancer group. The average age of the participants was $63( \pm 10)$ years and there was no difference between the groups $(p>0.05)$. Cancer staging was I-3\%, II-24\%, III-38\%, and IV-35\%. 


\begin{tabular}{|c|c|c|c|c|c|c|c|c|c|c|c|c|c|}
\hline & \multirow[b]{2}{*}{ Characteristic } & \multicolumn{2}{|l|}{ IgE } & \multicolumn{2}{|l|}{ IL-2 } & \multicolumn{2}{|l|}{ IL-4 } & \multicolumn{2}{|l|}{ IL-17 } & \multicolumn{2}{|l|}{ IL-1 $\beta$} & \multicolumn{2}{|l|}{ TGF- $\beta$} \\
\hline & & Median & $p$ & Median & $p$ & Median & $p$ & Median & $p$ & Median & p & Median & p \\
\hline \multirow{2}{*}{ Group } & Control & 192.7 & \multirow{2}{*}{0.158} & 52.0 & \multirow{2}{*}{0.139} & 31.9 & \multirow{2}{*}{0.005} & 573.9 & \multirow{2}{*}{0.001} & 7.3 & \multirow{2}{*}{0.060} & 495.9 & \multirow{2}{*}{0.000} \\
\hline & Cancer & 93.7 & & 66.3 & & 23.6 & & 373.7 & & 5.3 & & 969.8 & \\
\hline \multirow{2}{*}{ Reported allergies } & Absent & 108.8 & \multirow{2}{*}{0.690} & 58.6 & \multirow{2}{*}{0.561} & 28.7 & \multirow{2}{*}{0.119} & 404.2 & \multirow{2}{*}{0.075} & 5.4 & \multirow{2}{*}{0.772} & 737.1 & \multirow{2}{*}{0.605} \\
\hline & Present & 54.1 & & 58.0 & & 31.1 & & 540.0 & & 5.5 & & 750.0 & \\
\hline \multirow{4}{*}{ Tumor type } & Control & 192.7 & - & 52.0 & - & 31.9 & - & 573.9 & - & 7.3 & - & 495.9 & - \\
\hline & Prostate & 96.5 & 0.191 & 52.7 & 0.837 & 12.4 & 0.001 & 492.4 & 0.034 & 4.2 & 0.012 & 1193.5 & 0.001 \\
\hline & HNSCC & 188.6 & 0.766 & 86.7 & 0.005 & 25.0 & 0.045 & 235.5 & 0.001 & 6.5 & 0.635 & 659.5 & 0.071 \\
\hline & Stomach & 34.3 & 0.065 & 58.1 & 0.511 & 26.7 & 0.046 & 404.2 & 0.004 & 5.3 & 0.049 & 1107.0 & 0.001 \\
\hline \multirow{5}{*}{ Staging General Cancer } & Control & 192.7 & - & 52.0 & - & 31.9 & - & 573.9 & - & 7.3 & - & 495.9 & - \\
\hline & I & 12.1 & 0.045 & 74.7 & 0.265 & 31.2 & 0.974 & 319.8 & 0.053 & 9.2 & 0.839 & 722.7 & 0.819 \\
\hline & II & 51.9 & 0.052 & 46.0 & 0.773 & 25.1 & 0.043 & 436.1 & 0.029 & 4.5 & 0.041 & 926.7 & 0.019 \\
\hline & III & 77.3 & 0.244 & \begin{tabular}{|l|}
69.7 \\
\end{tabular} & 0.113 & 25.5 & 0.008 & 420.4 & 0.002 & 5.0 & 0.029 & 1301.5 & 0.000 \\
\hline & IV & 188.6 & 0.555 & 86.7 & 0.092 & 20.4 & 0.014 & 286.0 & 0.001 & 5.6 & 0.319 & 810.4 & 0.026 \\
\hline
\end{tabular}

Table 2. Relationship among cancer, reported allergies, $\operatorname{IgE}(\mathrm{UI} / \mathrm{ml})$, and cytokine $(\mathrm{pg} / \mathrm{ml})$ concentration. Kruskal-Wallis test. Comparisons in relation to the Control Group, or to the Reported Allergies Absent Subgroup. Values are presented as median. Groups: Control $(n=20)$ and General Cancer $(n=60)$, that was the sum of three subgroups: Prostate $(n=20), \operatorname{HNSCC}(n=20)$, and Stomach $(n=20)$ Cancer. Reported allergies absent $(n=48)$ and present $(n=22)$. Staging General Cancer I $(n=3)$, II $(n=14)$, III $(n=23)$, IV $(n=20)$. Abbreviations: $\operatorname{IgE}=$ immunoglobulin $\mathrm{E}, \mathrm{IL}=$ interleukin, $\mathrm{TGF}=$ transforming growth factor, $\mathrm{HNSCC}=$ head and neck squamous cell carcinoma. Staging based on AJCC Cancer Staging Manual, 8th ed. ${ }^{43}$.

Allergies were reported in $50 \%$ of the control group and in only $20 \%$ of the cancer group (OR $0.46,95 \%$ CI $0.26-0.81, p=0.009)$. There was an inverse relation in the comparison between the control group and the prostate adenocarcinoma group (OR $0.17,95 \%$ CI $0.04-0.79, p=0.024)$. However, no difference was observed in the comparison with the gastric adenocarcinoma group (OR $0.25,95 \%$ CI $0.06-1.02, p=0.053$ ), or with the head and neck squamous cell carcinoma (HNSCC) group (OR $0.33,95 \%$ CI $0.09-1.27, p=0.108$ ). The most common type of allergy was rhinitis, which was observed in $15 \%$ of the cancer patients and in $35 \%$ of the control individuals $(p=0.005)$ (Table 1$)$.

The agreement between reported allergies and positive $\mathrm{IgE}$ (considered to be an $\mathrm{IgE}$ concentration $\geq 25 \mathrm{UI} / \mathrm{ml}$ ) was weak in all groups: $\kappa=0.000$ in the control group, $\kappa=0.002$ in the cancer patient group, namely $\kappa=-0.037$ for prostate adenocarcinoma, $\kappa=0.237$ for gastric adenocarcinoma, and $\kappa=-0.250$ for HNSCC.

An IL-2 increase was observed in HNSCC patients in relation to the control $(p=0.005)$. In the cancer patient group, there was a reduction in IL-4 (prostate: $p=0.001$, HNSCC: $p=0.045$, gastric: $p=0.046$ ), IL-17 (prostate: $p=0.034$, HNSCC: $p=0.001$, gastric: $p=0.004$ ), and IL- $\beta$ (prostate: $p=0.012$, gastric: $p=0.049$ ), and an increase in TGF- $\beta$ for this group (prostate: $p=0.001$ and gastric: $p=0.001$ ). No relation was observed between cytokines and cancer staging. (Table 2).

There was no difference in the values of cytokine medians between the two groups, based on IgE concentrations or on the classification of IgE in the normal, borderline, or high categories ( $p>0.05)$ (Table 3). There was a weak correlation between most cytokines and IgE levels in both groups (Spearman's correlation factors $<0.4$ for most groups $)^{45}$. A moderate correlation was identified only in the prostate adenocarcinoma group for TGF- $\beta$ $(\mathrm{r}=0.54, p=0.01)$ and IL-17 $(\mathrm{r}=0.42, p=0.06)$ as well as for gastric adenocarcinoma $(\mathrm{r}=0.40, p=0.07)$ for IL-2 (Fig. 1). There was no correlation between IgE concentrations and staging in the general cancer group $(r=0.25$, $p=0.60)$, prostate cancer $(\mathrm{r}=0.12, p=0.62)$, HNSCC $(\mathrm{r}=0.07, p=0.78)$, and stomach cancer $(\mathrm{r}=0.22, p=0.37)$.

To determine whether the presence of reported allergies is associated with the predominance of some immunity markers, cytokines (Th1 (IL-2), Th2 (IL-4), Th17 (IL-17), IL-1 $\beta$, TGF- $\beta$ ) and IgE were compared between both groups. Table 4 shows there was no difference among these variables in this study.

\section{Discussion}

The relation between cancer and allergies has been studied since the $1950 \mathrm{~s}^{46}$, and has yielded conflicting results, due to the diversity of study methods and to risk factors for cancer or allergies, such as age, use of medication and associated diseases, often not controlled ${ }^{6,38,39}$. These variables were observed and carefully adjusted in this study, to avoid interfering in the interpretation of results and to preserve their reliability.

There was an inverse association between cancer and clinically detected allergies, which favors the theory of immune surveillance ${ }^{12,47}$, which is higher in allergic processes and may be associated with the damage on malignant cells ${ }^{1,5}$. In this study, as well as in other investigations conducted in the same line of research, there was a lower prevalence of allergies in cancer patients, especially in the presence of prostate adenocarcinoma, in comparison with the control group ${ }^{33,40}$. There was also an inverse association between reported allergies and the presence of HNSCC, as well as of gastric adenocarcinoma ${ }^{34,37,48,49}$. The lack of significance in this comparison in the present study, which was revealed only as a trend, is probably due to the small number of cases, although we have studied a larger number of individuals than has been described in the literature in similar studies ${ }^{38,39}$. 


\begin{tabular}{|c|c|c|c|c|c|}
\hline \multirow[b]{2}{*}{ Group } & \multirow[b]{2}{*}{ Cytokines } & \multicolumn{3}{|c|}{ IgE concentration classification } & \multirow[b]{2}{*}{$p$} \\
\hline & & \begin{tabular}{|l|}
$\begin{array}{l}\text { Normal } \\
(<25 \mathrm{UI} / \mathrm{ml})\end{array}$ \\
\end{tabular} & \begin{tabular}{|l} 
Borderline \\
(25-100 UI/ml)
\end{tabular} & \begin{tabular}{|l|} 
High \\
( $>100 \mathrm{UI} / \mathrm{ml})$
\end{tabular} & \\
\hline \multirow{5}{*}{ Control } & IL-2 & \begin{tabular}{|l|}
48.15 \\
$(35.00-58.48)$
\end{tabular} & \begin{tabular}{|l|}
56.45 \\
$(41.07-70.22)$ \\
\end{tabular} & \begin{tabular}{|l|}
53.62 \\
$(3.82-102.20)$ \\
\end{tabular} & 0.651 \\
\hline & IL-4 & \begin{tabular}{|l|}
32.69 \\
$(31.89-34.29)$
\end{tabular} & \begin{tabular}{|l|}
31.89 \\
$(29.48-32.69)$
\end{tabular} & \begin{tabular}{|l|}
30.28 \\
$(26.28-35.89)$
\end{tabular} & 0.221 \\
\hline & IL-17 & \begin{tabular}{|l|}
515.73 \\
$(333.65-617.73)$ \\
\end{tabular} & \begin{tabular}{|l|}
562.44 \\
$(386.08-688.28)$ \\
\end{tabular} & \begin{tabular}{|l|}
584.37 \\
$(220.21-747.38)$
\end{tabular} & 0.691 \\
\hline & IL1- $\beta$ & $\begin{array}{l}4.51 \\
(3.93-5.40)\end{array}$ & \begin{tabular}{|l|}
7.38 \\
$(2.51-16.21)$
\end{tabular} & \begin{tabular}{|l|}
8.19 \\
$(3.22-20.06)$
\end{tabular} & 0.074 \\
\hline & TGF- $\beta$ & \begin{tabular}{|l|}
496.35 \\
$(483.30-1,586.00)$
\end{tabular} & \begin{tabular}{|l|}
517.20 \\
$(491.90-706.80)$
\end{tabular} & \begin{tabular}{|l|}
493.60 \\
$(479.50-1,318.00)$
\end{tabular} & 0.611 \\
\hline \multirow{5}{*}{ General cancer } & IL-2 & \begin{tabular}{|l|}
62.63 \\
$(0.74-203.69)$
\end{tabular} & $\begin{array}{l}48.11 \\
(0.67-107.34)\end{array}$ & $\begin{array}{l}78.51 \\
(0.49-1,025,523.40)\end{array}$ & 0.329 \\
\hline & IL-4 & $\begin{array}{l}27.80 \\
(0.80-60.00)\end{array}$ & $\begin{array}{l}28.54 \\
(6.40-57.60)\end{array}$ & $\begin{array}{l}21.60 \\
(1.60-68.40)\end{array}$ & 0.465 \\
\hline & IL-17 & \begin{tabular}{|l|}
376.07 \\
$(128.69-612.97)$
\end{tabular} & \begin{tabular}{|l|}
350.33 \\
$(171.59-688.28)$
\end{tabular} & $\begin{array}{l}404.19 \\
(98.19-898.95)\end{array}$ & 0.776 \\
\hline & IL1- $\beta$ & \begin{tabular}{|l|}
5.55 \\
$(0.83-23.92)$
\end{tabular} & $\begin{array}{l}4.89 \\
(2.71-12.40)\end{array}$ & $\begin{array}{l}5.20 \\
(0.53-17.48)\end{array}$ & 0.611 \\
\hline & TGF- $\beta$ & \begin{tabular}{|l|}
952.55 \\
$(278.40-1,784.00)$
\end{tabular} & \begin{tabular}{|l|}
965.05 \\
$(485.20-1,672.00)$
\end{tabular} & $\begin{array}{l}, 111.50 \\
(14.70-2,155.00)\end{array}$ & 0.866 \\
\hline \multirow{5}{*}{$\begin{array}{l}\text { Prostate } \\
\text { Cancer }\end{array}$} & IL-2 & \begin{tabular}{|l}
107.30 \\
$(1.08-133.62)$
\end{tabular} & \begin{tabular}{|l|l}
48.25 \\
$(0.67-107.34)$
\end{tabular} & $\begin{array}{l}49.67 \\
(0.49-79.97)\end{array}$ & 0.242 \\
\hline & IL-4 & \begin{tabular}{|l|}
5.20 \\
$(3.60-45.60)$
\end{tabular} & \begin{tabular}{|l|}
9.60 \\
$(6.40-30.00)$
\end{tabular} & \begin{tabular}{|l}
25.80 \\
$(2.00-41.20)$
\end{tabular} & 0.743 \\
\hline & IL-17 & \begin{tabular}{|l|}
543.38 \\
$(266.92-595.81)$
\end{tabular} & \begin{tabular}{|l|}
436.61 \\
$(190.66-600.57)$
\end{tabular} & \begin{tabular}{|l|}
478.55 \\
$(178.27-898.95)$
\end{tabular} & 0.594 \\
\hline & IL1- $\beta$ & \begin{tabular}{|l|}
5.45 \\
$(3.77-19.71)$
\end{tabular} & $\begin{array}{l}4.71 \\
(3.77-12.40)\end{array}$ & $\begin{array}{l}3.27 \\
(0.53-10.27)\end{array}$ & 0.108 \\
\hline & TGF- $\beta$ & \begin{tabular}{|l|}
$1,241.00$ \\
$(655.10-1,784.00)$
\end{tabular} & \begin{tabular}{|l|}
771.50 \\
$(490.60-1,275.00)$
\end{tabular} & \begin{tabular}{|l|}
$1,370.00$ \\
$(495.20-2,155.00)$
\end{tabular} & 0.091 \\
\hline \multirow{5}{*}{ HNSCC } & IL-2 & $\begin{array}{l}68.65 \\
(1.27-203.69)\end{array}$ & \begin{tabular}{|l|}
81.43 \\
$(70.84-92.01)$
\end{tabular} & \begin{tabular}{|l|}
96.57 \\
$(0.59-1,025,523.40)$
\end{tabular} & 0.383 \\
\hline & IL-4 & \begin{tabular}{|l}
25.40 \\
$(0.80-39.20)$
\end{tabular} & \begin{tabular}{|l|}
56.80 \\
$(56.00-57.60)$
\end{tabular} & $\begin{array}{l}21.40 \\
(1.60-68.40)\end{array}$ & 0.123 \\
\hline & IL-17 & \begin{tabular}{|l|}
229.74 \\
$(157.29-612.97)$
\end{tabular} & \begin{tabular}{|l|}
216.87 \\
$(208.77-224.98)$
\end{tabular} & \begin{tabular}{|l|}
285.99 \\
$(98.19-636.80)$
\end{tabular} & 0.891 \\
\hline & IL1- $\beta$ & \begin{tabular}{|l}
7.71 \\
$(3.83-23.92)$
\end{tabular} & $\begin{array}{l}4.61 \\
(2.71-6.52)\end{array}$ & $\begin{array}{l}5.60 \\
(2.56-17.48)\end{array}$ & 0.404 \\
\hline & TGF- $\beta$ & \begin{tabular}{|l|}
810.35 \\
$(278.40-1,241.00)$
\end{tabular} & \begin{tabular}{|l|}
565.85 \\
$(485.20-646.50)$
\end{tabular} & \begin{tabular}{|l|}
780.10 \\
$(486.60-1,939.00)$
\end{tabular} & 0.409 \\
\hline \multirow{5}{*}{$\begin{array}{l}\text { Stomach } \\
\text { Cancer }\end{array}$} & IL-2 & $\begin{array}{l}55.51 \\
(0.74-92.37)\end{array}$ & $\begin{array}{l}33.78 \\
(0.69-79.24)\end{array}$ & $\begin{array}{l}96.02 \\
(34.19-112.80)\end{array}$ & 0.068 \\
\hline & IL-4 & \begin{tabular}{|l|}
29.48 \\
$(6.00-60.00)$
\end{tabular} & \begin{tabular}{|l}
31.49 \\
$(8.80-53.20)$
\end{tabular} & $\begin{array}{l}18.00 \\
(2.40-28.68)\end{array}$ & 0.152 \\
\hline & IL-17 & \begin{tabular}{|l|}
453.77 \\
$(128.69-553.86)$
\end{tabular} & \begin{tabular}{|l|}
418.49 \\
$(171.59-688.28)$
\end{tabular} & $\begin{array}{l}387.04 \\
(196.38-605.34)\end{array}$ & 0.655 \\
\hline & IL1- $\beta$ & \begin{tabular}{|l}
4.64 \\
$(0.83-11.84)$
\end{tabular} & $\begin{array}{l}4.89 \\
(3.77-6.16)\end{array}$ & \begin{tabular}{|l|}
5.75 \\
$(2.66-8.80)$
\end{tabular} & 0.560 \\
\hline & TGF- $\beta$ & \begin{tabular}{|l|}
784.40 \\
$(500.00-1784.00)$
\end{tabular} & \begin{tabular}{|l|}
$1,279.50$ \\
$(663.70-1672.00)$
\end{tabular} & \begin{tabular}{|l|}
$1,189.00$ \\
$(14.70-1629.00)$
\end{tabular} & 0.462 \\
\hline
\end{tabular}

Table 3. Cytokine (pg/ml) values among groups and $\mathrm{IgE}(\mathrm{UI} / \mathrm{ml})$ concentrations. Kruskal-Wallis Test. Values are presented as median (min-max). Groups: Control $(n=20)$ and General Cancer $(n=60)$, that was the sum of three subgroups: Prostate $(n=20)$, HNSCC $(n=20)$, and Stomach $(n=20)$ Cancer. Abbreviations: $\mathrm{IgE}=$ immunoglobulin $\mathrm{E}, \mathrm{IL}=$ interleukin, $\mathrm{TGF}=$ transforming growth factor, $\mathrm{HNSCC}=$ head and neck squamous cell carcinoma. Classification of IgE Levels based on Wiemels JL et al. ${ }^{44}$.

A pivotal limitation of this work was the low number of participants per group due to the specificity of cancers, which were investigated. The rigorous statistical analysis of all parameters leads this study suitable to drive conclusions concerning the relationship between allergies and cancer. Other types of cancer could be included in this study, which belong to future surveys of the same line of research. These upcoming studies will expand the current data with more participants.

Allergy is a complex disorder that involves immune factors that may or may not depend on IgE, and few studies are available that evaluate the IgE serum dosage in cancer patients ${ }^{35,50-52}$. Although IgE is useful in detecting allergies, this immunoglobulin is not increased in all types of allergic reactions, which may explain 


\section{A - Control group}
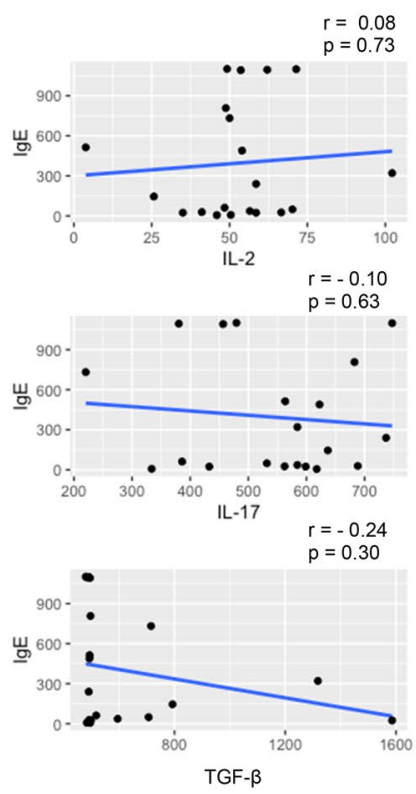

\section{C - HNSCC group}

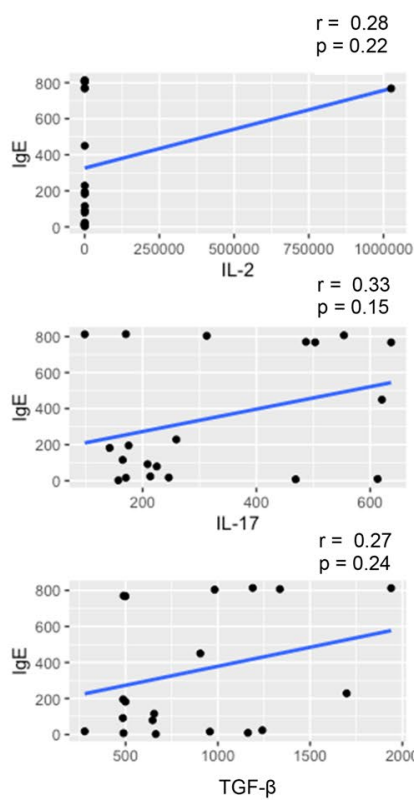

\section{B - Prostate cancer group}
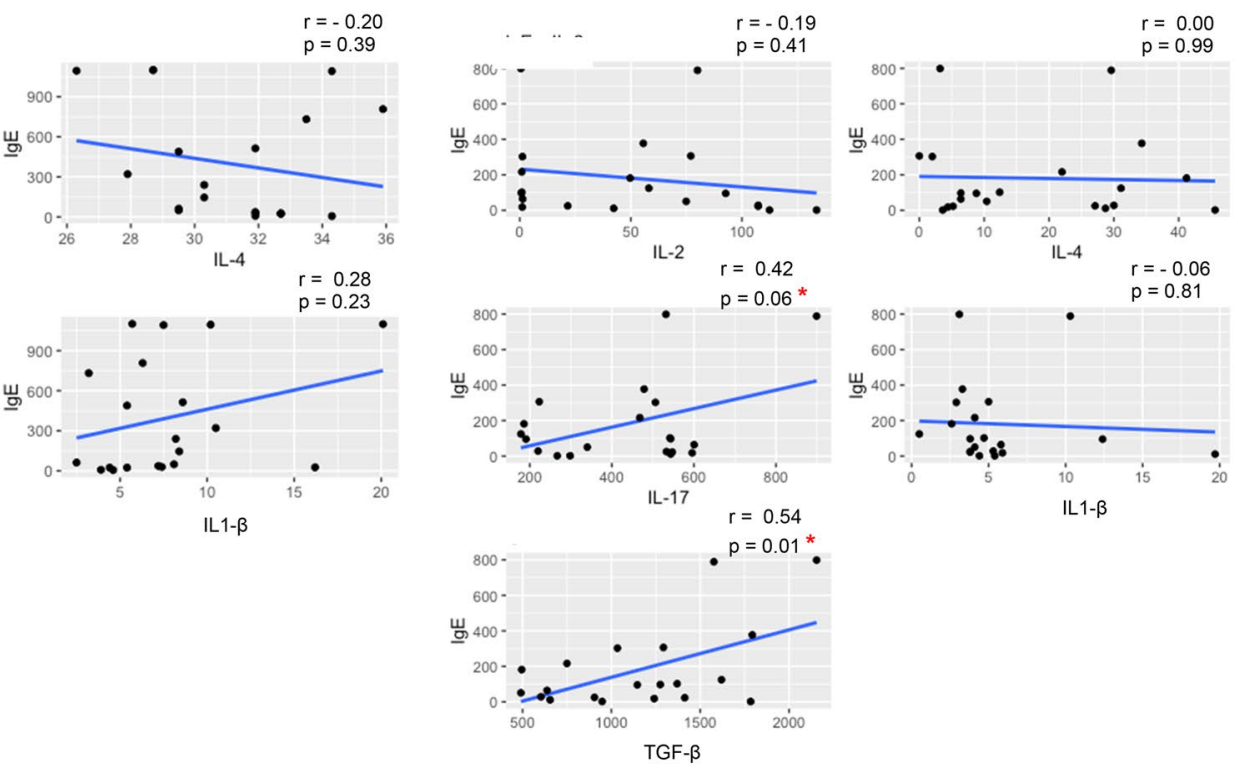

IL1- $\beta$

\section{D - Stomach cancer group}
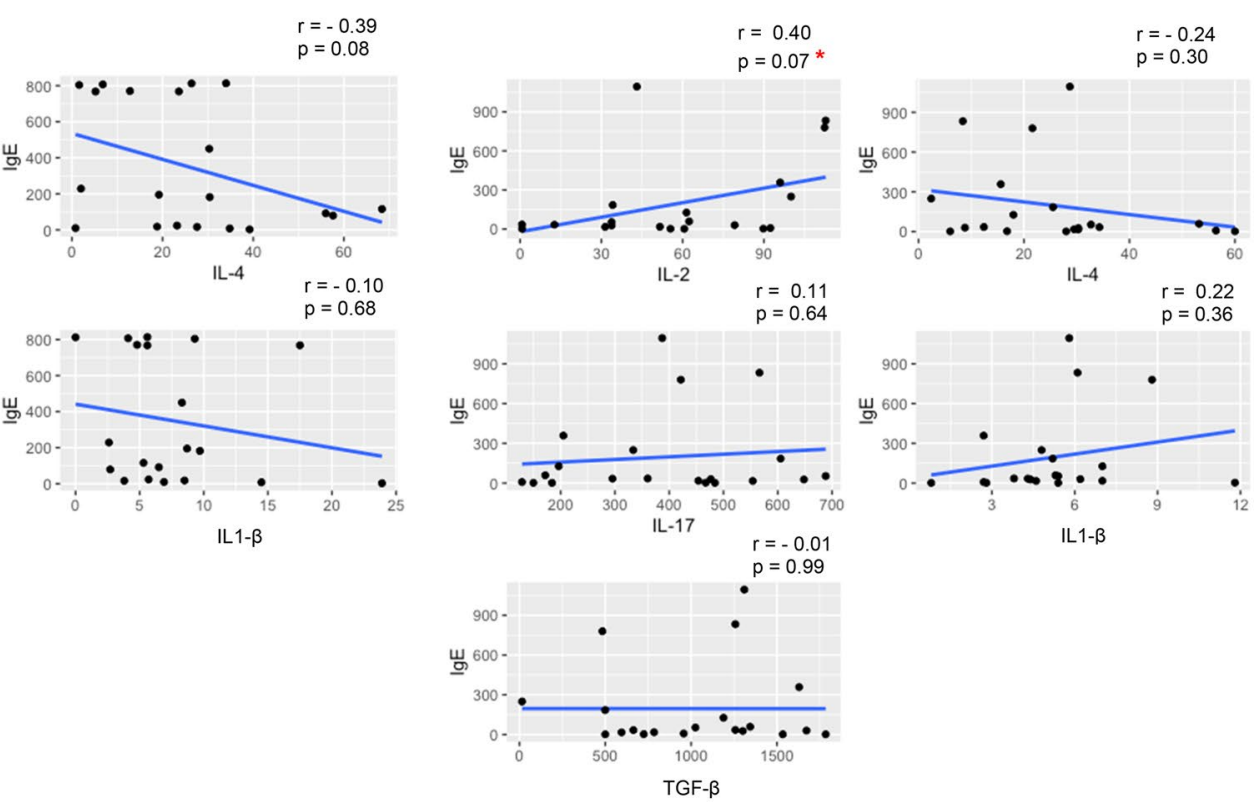

Figure 1. Dispersion diagrams and linear regression axes based on the correlation factors between cytokines $(\mathrm{pg} / \mathrm{ml})$ and $\mathrm{IgE}(\mathrm{UI} / \mathrm{ml})$, stratified by patient group. Spearman Correlation Test. ${ }^{\star}$ Groups with a moderate correlation (Devore JL $\left.{ }^{45}\right)$. Groups: Control $(n=20)$, Prostate cancer $(n=20)$, HNSCC $(n=20)$, Stomach cancer $(n=20)$. Abbreviations: $\mathrm{IgE}=\mathrm{immunoglobulin} \mathrm{E}, \mathrm{IL}=$ interleukin, $\mathrm{TGF}=$ transforming growth factor, HNSCC $=$ head and neck squamous cell carcinoma.

the low concordance between reported allergies and positive IgE observed in this work, likewise as was reported in another study ${ }^{44}$.

When the inverse association between cancer and allergies is detected, immune surveillance and immunoprophylaxis theories are mentioned as an explanation. Immune surveillance theory suggests that reactions to allergens increase the immune response, including the production of IgE and the activation of effector immune cells (monocytes, macrophages, natural killer cells, eosinophils, mastocytes, and basophils), capable of detecting and destroying cancer cells. Activation of the Th2 response observed in allergic conditions promote the synthesis of related cytokines, such as IL-4 and IL-3, which favors the synthesis of IgE against specific tumor antigens, capable of activating effector cells and destroying tumors ${ }^{19,36,37}$. Immunoprophylaxis theory is related to inhaled 


\begin{tabular}{|c|c|c|c|c|}
\hline \multirow[b]{2}{*}{ Group } & \multirow[b]{2}{*}{ Cytokines and IgE } & \multicolumn{2}{|c|}{ Reported allergies } & \multirow[b]{2}{*}{$p$} \\
\hline & & Absent & Present & \\
\hline \multirow{6}{*}{ Control } & IL-2 & 55.24 & 47.34 & 0.218 \\
\hline & IL-4 & 29.88 & 32.29 & 0.105 \\
\hline & IL-17 & 456.15 & 591.52 & 0.190 \\
\hline & IL1- $\beta$ & 5.55 & 7.81 & 0.218 \\
\hline & TGF- $\beta$ & 491.75 & 496.50 & 0.075 \\
\hline & $\operatorname{IgE}$ & 364.30 & 97.40 & 0.393 \\
\hline \multirow{6}{*}{ General cancer } & IL-2 & 64.637 & 67.739 & 0.956 \\
\hline & IL-4 & 23.6 & 24.337 & 0.763 \\
\hline & IL-17 & 363.68 & 414.681 & 0.890 \\
\hline & IL1- $\beta$ & 5.449 & 3.952 & 0.191 \\
\hline & TGF- $\beta$ & 956.9 & 1249.5 & 0.327 \\
\hline & $\operatorname{IgE}$ & 99.65 & 76.90 & 0.671 \\
\hline \multirow{6}{*}{ Prostate cancer } & IL-2 & 55.64 & 21.64 & 0.616 \\
\hline & IL-4 & 17.20 & 5.20 & 0.254 \\
\hline & IL-17 & 468.06 & 532.89 & 0.305 \\
\hline & IL1- $\beta$ & 4.69 & 3.77 & 0.146 \\
\hline & TGF- $\beta$ & 1146.00 & 1413.00 & 0.305 \\
\hline & $\operatorname{IgE}$ & 97.39 & 85.20 & 0.731 \\
\hline \multirow{6}{*}{ HNSCC } & IL-2 & 87.63 & 72.67 & 0.866 \\
\hline & IL-4 & 23.60 & 34.80 & 0.266 \\
\hline & IL-17 & 245.95 & 224.98 & 0.965 \\
\hline & IL1- $\beta$ & 6.72 & 5.65 & 0.964 \\
\hline & TGF- $\beta$ & 655.10 & 663.80 & 0.612 \\
\hline & $\operatorname{IgE}$ & 228.55 & 203.80 & 0.119 \\
\hline \multirow{6}{*}{ Stomach cancer } & IL-2 & 58.07 & 48.32 & 0.750 \\
\hline & IL-4 & 28.34 & 20.54 & 0.820 \\
\hline & IL-17 & 437.56 & 282.65 & 0.617 \\
\hline & IL1- $\beta$ & 5.42 & 4.48 & 0.211 \\
\hline & TGF- $\beta$ & 990.95 & 1301.00 & 0.494 \\
\hline & $\operatorname{IgE}$ & 117.47 & 121.65 & 0.211 \\
\hline
\end{tabular}

Table 4. Cytokine (pg/ml) and $\mathrm{IgE}(\mathrm{UI} / \mathrm{ml})$ values among the groups and reported allergies. KruskalWallis Test. Groups: Control $(n=20)$ and General Cancer $(n=60)$, that was the sum of three subgroups: Prostate $(n=20)$, HNSCC $(n=20)$, and Stomach $(n=20)$ Cancer. Abbreviations: $\operatorname{IgE}=$ immunoglobulin E, $\mathrm{IL}=$ interleukin, $\mathrm{TGF}=$ transforming growth factor, $\mathrm{HNSCC}=$ head and neck squamous cell carcinoma.

antigens and allergic reaction manifestations (coughing, sneezing, etc.) intended to eliminate these antigens by means of IgE and activated effector cells that damage and remove infectious microorganisms, mutagenic toxins, and environmental carcinogens ${ }^{34,36,37}$.

Only two studies evaluated the measurement of cytokines and other biomarkers, connecting cancer and allergies $^{38,39}$. In a study comparing cytokines from HNSCC to the allergic rhinitis group and the control group (with no cancer or allergies), no difference was observed among the concentrations of the studied cytokines (response Th1 (IL-2, IL-12, IFN- $\gamma$, TNF- $\alpha$ ), Th2 (IL-4, IL5, IL-13), innate immunity (IL-1 $\beta$, IL-8, IL-17), innate immunity (MCP)-1, macrophage inflammatory protein (MIP)-1 $\beta$, granulocyte and macrophage colony stimulating factor (G-CSF), granulocyte and macrophage colony stimulating factor (GM-CSF), and immunity related to the T cells (IL-6, IL-7, IL-10) ${ }^{38}$. A different study with breast cancer patients revealed no differences in cytokine concentrations (IL-1 $\beta$, IL-6, IFN- $\gamma$, IL-4) between the cancer and allergy groups ${ }^{39}$.

The fact that groups were not paired by age, which may have interfered in the results, as the immune response changes with age, and that a lower number of patients, if compared to the present work, was involved, are limitations in these two previous studies ${ }^{38,39}$. Results in this study, as well as in those mentioned in the literature, indicated no difference in cytokines related to Th1 and Th2 parameters in the association between cancer and allergic processes related to type I hypersensitivity reactions. This finding contradicts one of the proposed theories in epidemiological study literature about cancer and allergy, in which a difference in cytokines related to Th1 and Th2 parameters had been suggested ${ }^{19,36,37}$.

New studies have increased the knowledge beyond the immune system's Th1/Th2 paradigm and other subsets of cells involved in this process, such as Th3, Th17, Th9, follicular Th, and regulatory T, illustrating that these interrelations are broader. An additional hypothesis, other than the Th1/Th2 paradigm, is based on publications arguing that T CD4+ lymphocytes exhibit plasticity and do not behave as inflexible Th1 or Th2, producing only a 
few cytokines ${ }^{53,54}$, despites being flexible in the synthesis of mediators and in the conversion of effector cells Th1, Th2, Th17, or regulatory $\mathrm{T}^{21-23,55}$. Based on the action of certain cytokines, a subset of $\mathrm{T}$ cells may be transformed into different cytokine secretory cells $\mathrm{s}^{21-23,55,56}$.

Immune modulating cytokines (TGF- $\beta$, IL-10, IL-17, and IL-23) facilitate tumor development, while others (IFN- $\gamma$, TNF- $\alpha$, GM-CSF, IL-2, IL-6, IL-17, and IL-12) promote immune surveillance and delay its growth ${ }^{19,57}$. Studies discussing cancer and allergies must evaluate these literature findings.

To determine whether there is a correlation of other mediators potentially involved in the relation between cancer and allergies, other cytokines were studied. An increase in regulatory cytokine IL- 2 and TGF- $\beta$ was detected, as was the reduction of IL- 4 , IL-17, and IL- $1 \beta$, reflecting the cancer patient's immunosuppressive environment and the lower prevalence of allergies. Such findings and characteristic cytokine levels in tumors confirm the specificity of the immune response according to the type of cancer ${ }^{32}$. The moderate correlation between IgE and IL-17 and TGF- $\beta$ in the prostate adenocarcinoma group suggests the presence of an allergy marker with immunosuppressive response and immune response specificity, according to the tumor type. Studies show that TGF- $\beta$ does not have a direct effect on the origin of the Th17 cells; however, it may favor its development to suppress the Th1 differentiation ${ }^{58,59}$.

A better understanding of the mechanisms involved in the relationship between cancer and allergies require studies involving a higher number of cytokines and their relation with the molecular messenger (messenger RNA) responsible for synthesizing the cytokines involved in allergies and inflammation ${ }^{23,60}$. Future studies should involve the evaluation, in control environments, of the immune system to exogenous antigens that trigger allergies in cancer patients, in a dynamic study of antigen stimulus and its response in the immune system ${ }^{61-63}$.

\section{Conclusions}

There was an inverse association between cancer and clinical allergy manifestations. In head and neck, stomach, and prostate cancers, an immunosuppressive serum tumor environment was predominant. There was no difference in cytokines related to Th1 and Th2 parameters in relation to IgE. No correlation was found between clinically proved allergies and immunity markers related to the same allergens.

\section{Methods}

Ethics approval and consent to participate. This research was carried out according to the principles set out in the Declaration of Helsinki 1964 and all subsequent revisions. This work was approved by the Research Ethics Committee of the Hospital Foundation of the State of Minas Gerais, under protocol number 075/2009. Informed consent was obtained from all participants.

Patient recruitment, characteristics and sample collection. This control case research evaluated the cytokines related to the Th1 (IL-2) and Th2 (IL-4) parameters, in relation to the IgE levels, and to reported allergies in control individuals and cancer patients. The levels of immune mediators involved in the Th17 (IL-17) response, in both immunosuppression/immunoregulation (TGF- $\beta$ ) and IL1- $\beta$ pro-inflammation in relation to IgE levels and to reported allergies in control individuals and cancer patients were also evaluated.

This study included patients with a recent histological diagnosis of cancer and they were only admitted to the research before undergoing any type of treatment. The individuals included were older than 18 years of age, from both genders, who presented an Eastern Cooperative Oncology Group (ECOG) performance score between zero and $\mathrm{two}^{42}$, TNM staging from I to $\mathrm{IV}^{43}$, and no previous history of other cancer, autoimmune disease or immune treatment, corticosteroid therapy, chemotherapy, or radiation therapy.

The control group consisted of 20 volunteers, with no cancer and using no medications, selected by age to be paired with the cancer group. The clinical assessment was conducted to identify addictions, alcoholism and smoking, associated diseases, medications, allergy history, allergy type (allergic rhinitis, atopic dermatitis, asthma, food and drug allergies), as well as allergic symptoms after exposure to certain allergens, such as medication, food, dust, mold, or animals. Information related to allergy was specifically asked to all patients and volunteers, emphasizing details related to each allergic manifestation. All reported allergies were proved by medical diagnosis, identifying allergens for each case.

The present study included 60 cancer patients, distributed in three subgroups $(n=20)$, gastric adenocarcinoma, prostate adenocarcinoma, and head and neck squamous cell carcinoma (HNSCC). These tumors were selected because they exhibited an inverse relation with allergies in a previous epidemiological study, within the same line of research ${ }^{40}$. All patients in both groups were identified by gender and age. Cancer patients were subjected to the same clinical assessment as the control group, regarding allergies and their relation to cancer, considering its histology, location, staging, and diagnostic data.

Serum cytokine dosages were obtained using the ELISA method, in accordance with manufacturer instructions. This study reviewed total IgE (ALPCO, Salem, NH, USA), IL-2 (Enzo Life Sciences, Farmingdale, NY, USA), IL-4 (Enzo Life Sciences, Farmingdale, NY, USA), TGF- $\beta$ (Xpressbio Life Science, Frederick, MD, USA), IL1- $\beta$ (Xpressbio Life Science, Frederick, MD, USA), and IL-17 (Xpressbio Life Science, Frederick, MD, USA).

Statistical analysis. Statistical analyses were conducted using the Statistical Package for the Social Sciences software, version 25 [https://www.ibm.com/support/pages/downloading-ibm-spss-statistics-25] ${ }^{44}$. The Kolmogorov-Smirnov normality test was conducted to assess the normality of each parameter. A non-parametric test was used when there was no normal data, and a parametric test was used to compare normal data averages, with their respective standard deviations. An odds ratio (OR) with a 95\% confidence interval was used to evaluate the association with a risk factor, which indicates association if value 1 is not involved. The correlation among the 
variables was done by Spearman's correlation. Multiple comparisons were done by the Kruskal-Wallis test. All tests were two-tailed and the difference amount was considered to be significant, if it corresponded to $p<0.05$.

The correlation levels, according to Spearman's factors, were classified as very weak (0.00 to 0.19$)$, weak ( 0.20 to 0.39 ), moderate $(0.40$ to 0.69$)$, strong ( 0.70 to 0.89 ), and very strong ( 0.90 to 1.00$)^{45}$. The kappa factor evaluated the concordance between IgE positivity and reported allergies, and it was classified as weak $(\kappa \leq 0.40)$, intermediate $(0.40 \leq \kappa \leq 0.75)$, and strong $(\kappa \geq 0.75)^{44}$.

Received: 25 April 2021; Accepted: 10 August 2021

Published online: 13 September 2021

\section{References}

1. Jensen-Jarolim, E. et al. AllergoOncology - the impact of allergy in oncology: EAACI position paper. Allergy 72(6), 866-887 (2017).

2. Rigoni, A., Colombo, M. P. \& Pucillo, C. Mast cells, basophils and eosinophils: From allergy to cancer. Semin. Immunol. 35, 29-34 (2018).

3. Palm, N. W., Rosenstein, R. K. \& Medzhitov, R. Allergic host defences. Nature 484(7395), 465-472 (2012).

4. Pulendran, B. \& Artis, D. New paradigms in type 2 immunity. Science 337(6093), 431-435 (2012).

5. Hoste, E., Cipolat, S. \& Watt, F. M. Understanding allergy and cancer risk: what are the barriers?. Nat. Rev. Cancer. 15(3), 131-132 (2015).

6. Kozłowska, R., Bożek, A. \& Jarząb, J. Association between cancer and allergies. Allergy Asthma Clin. Immunol. 12, 39 (2016).

7. Platzer, B. et al. IgE/FceRI-mediated antigen cross-presentation by dendritic cells enhances anti-tumor immune responses. Cell Rep. 10, 1487 (2015).

8. Ockert, D., Schmitz, M., Hampl, M. \& Rieber, E. P. Advances in cancer immunotherapy. Immunol. Today. 20(2), 63-65 (1999).

9. Jensen-Jarolim, E. et al. AllergoOncology: The role of IgE-mediated allergy in cancer. Allergy 63(10), 1255-1266 (2008).

10. Jensen-Jarolim, E., Turner, M. C. \& Karagiannis, S. N. AllergoOncology: IgE- and IgG4-mediated immune mechanisms linking allergy with cancer and their translational implications. J. Allergy Clin. Immunol. 140(4), 982-984 (2017).

11. Neuchrist, C. et al. Distribution of immunoglobulins in squamous cell carcinoma of the head and neck. Int. Arch. Allergy Immunol. 104(1), 97-100 (1994).

12. Kumar, S., Saini, R. V. \& Mahindroo, N. Recent advances in cancer immunology and immunology-based anticancer therapies. Biomed. Pharmacother. 96, 1491-1500 (2017).

13. Finn, O. J. Immuno-oncology: Understanding the function and dysfunction of the immune system in cancer. Ann. Oncol. 23(Suppl 8), 6-9 (2012).

14. Yarchoan, R. \& Uldrick, T. S. HIV-Associated Cancers and Related Diseases. N. Engl. J. Med. 378(11), 1029-1041 (2018).

15. Whiteside, T. L. Immune suppression in cancer: Effects on immune cells, mechanisms and future therapeutic intervention. Semin. Cancer Biol. 16(1), 3-15 (2006).

16. Feldman, C. H., Liu, J., Feldman, S., Solomon, D. H. \& Kim, S. C. Risk of high-grade cervical dysplasia and cervical cancer in women with systemic lupus erythematosus receiving immunosuppressive drugs. Lupus 26(7), 682-689 (2017).

17. Garritsen, F. M. et al. Risk of non-melanoma skin cancer in patients with atopic dermatitis treated with oral immunosuppressive drugs. Acta Derm. Venereol. 97(6), 724-730 (2017).

18. Jensen-Jarolim, E. \& Pawelec, G. The nascent field of AllergoOncology. Cancer Immunol. Immunother. 61(9), 1355-1357 (2012).

19. Jensen-Jarolim, E. et al. AllergoOncology: Opposite outcomes of immune tolerance in allergy and cancer. Allergy 73(2), 328-340 (2018).

20. Amirian, E. S. et al. Approaching a scientific consensus on the association between allergies and glioma risk: A report from the Glioma International Case-Control Study. Cancer Epidemiol. Biomark. Prev. 25(2), 282-290 (2016).

21. Wan, Y. Y. Multi-tasking of helper T cells. Immunology 130(2), 166-171 (2010).

22. O'Shea, J. J. \& Paul, W. E. Mechanisms underlying lineage commitment and plasticity of helper CD4+ T cells. Science 327(5969), 1098-1102 (2010).

23. Cosmi, L., Maggi, L., Santarlasci, V., Liotta, F. \& Annunziato, F. T helper cells plasticity in inflammation. Cytometry A. 85(1), 36-42 (2014).

24. Hirahara, K. et al. Mechanisms underlying helper T-cell plasticity: Implications for immune-mediated disease. J. Allergy Clin. Immunol. 131(5), 1276-1287 (2013).

25. Gianchecchi, E. \& Fierabracci, A. Inhibitory receptors and pathways of lymphocytes: The role of PD-1 in Treg development and their involvement in autoimmunity onset and cancer progression. Front Immunol. 9, 2374 (2018).

26. Takeuchi, Y. \& Nishikawa, H. Roles of regulatory T cells in cancer immunity. Int. Immunol. 28(8), 401-409 (2016).

27. Palomo, J., Dietrich, D., Martin, P., Palmer, G. \& Gabay, C. The interleukin (IL)-1 cytokine family-Balance between agonists and antagonists in inflammatory diseases. Cytokine 76(1), 25-37 (2015).

28. Netea, M. G., van de Veerdonk, F. L., van der Meer, J. W., Dinarello, C. A. \& Joosten, L. A. Inflammasome-independent regulation of IL-1-family cytokines. Annu. Rev. Immunol. 33, 49-77 (2015).

29. Lin, R. L. \& Zhao, L. J. Mechanistic basis and clinical relevance of the role of transforming growth factor- $\beta$ in cancer. Cancer Biol. Med. 12(4), 385-393 (2015).

30. Tirado-Rodriguez, B., Ortega, E., Segura-Medina, P. \& Huerta-Yepez, S. TGF- $\beta$ : an important mediator of allergic disease and a molecule with dual activity in cancer development. J. Immunol. Res. 2014, 318481 (2014).

31. Blobe, G. C., Schiemann, W. P. \& Lodish, H. F. Role of transforming growth factor beta in human disease. N. Engl. J. Med. 342(18), 1350-1358 (2000).

32. Lippitz, B. E. Cytokine patterns in patients with cancer: a systematic review. Lancet Oncol. 14(6), e218-228 (2013).

33. Carneiro, B. G. M. C., Petroianu, A., Resende, V. \& Alberti, L. R. Relação entre câncer, alergia e imunomediadores. Revista Médica de Minas Gerais. 27(e-1877), 1-6 (2017).

34. Liao, H. C. et al. Allergy symptoms, serum total immunoglobulin E, and risk of head and neck cancer. Cancer Causes Control. 27(9), 1105-1115 (2016).

35. Bożek, A. et al. Can atopy have a protective effect against cancer?. PLoS ONE 15(2), e0226950 (2020).

36. Josephs, D. H., Spicer, J. F., Corrigan, C. J., Gould, H. J. \& Karagiannis, S. N. Epidemiological associations of allergy, IgE and cancer. Clin. Exp. Allergy. 43(10), 1110-1123 (2013).

37. Cui, Y. \& Hill, A. W. Atopy and specific cancer sites: A review of epidemiological studies. Clin. Rev. Allergy Immunol. 51(3), 338-352 (2016).

38. Millrud, C. R. et al. Inverse immunological responses induced by allergic rhinitis and head and neck squamous cell carcinoma. PLoS ONE 9(1), e86796 (2014).

39. Kowalczewska, M. E. et al. Analysis of the involvement of cytokines in allergy and breast cancer association. Contemp Oncol (Pozn). 18(6), 396-402 (2014). 
40. Petroianu, A., Chaves, D. N. \& De Oliveira, O. Comparative incidence of allergy in the presence or absence of cancer. J. Int. Med. Res. 23(5), 358-363 (1995).

41. Carneiro, B. G. M. C. \& Petroianu, A. The relationship between cancer and allergy. Appl. Cancer Res.. 31(4), 3 (2011).

42. Oken, M. M. et al. Toxicity and response criteria of the Eastern Cooperative Oncology Group. Am. J. Clin. Oncol. 5(6), 649-655 (1982).

43. Amid, M. E. AJCC Cancer Staging Manual (Springer, 2017).

44. Wiemels, J. L. et al. Reduced immunoglobulin E and allergy among adults with glioma compared with controls. Cancer Res. 64(22), 8468-8473 (2004).

45. Devore, J. L. Probability and Statistics for Engineering and the Sciences 8th edn. (Cengage Learning, 2011).

46. Logan, J. \& Saker, D. The incidence of allergic disorders in cancer. N. Z. Med. J. 52(289), 210-212 (1953).

47. Wulaningsih, W. et al. Investigating the association between allergen-specific immunoglobulin E, cancer risk and survival. Oncoimmunology. 5(6), e1154250 (2016).

48. Hsiao, J. R. et al. Allergies and risk of head and neck cancer: an original study plus meta-analysis. PLoS ONE 8(2), e55138 (2013).

49. El-Zein, M. et al. History of asthma or eczema and cancer risk among men: a population-based case-control study in Montreal, Quebec, Canada. Ann. Allergy Asthma Immunol. 104(5), 378-384 (2010).

50. Gousias, K. et al. Frequent abnormalities of the immune system in gliomas and correlation with the WHO grading system of malignancy. J. Neuroimmunol. 226(1-2), 136-142 (2010).

51. Biggar, R. J. et al. Immunoglobulin subclass levels in patients with non-Hodgkin lymphoma. Int. J. Cancer. 124(11), 2616-2620 (2009).

52. Wiemels, J. L. et al. Risk of squamous cell carcinoma of the skin in relation to IgE: A nested case-control study. Cancer Epidemiol. Biomark. Prev. 20(11), 2377-2383 (2011)

53. Mosmann, T. R., Cherwinski, H., Bond, M. W., Giedlin, M. A. \& Coffman, R. L. Two types of murine helper T cell clone. I. Definition according to profiles of lymphokine activities and secreted proteins. J. Immunol. 136(7), 2348-2357 (1986).

54. Abbas, A. K., Murphy, K. M. \& Sher, A. Functional diversity of helper T lymphocytes. Nature 383(6603), 787-793 (1996).

55. Hirahara, K. \& Nakayama, T. CD4+ T-cell subsets in inflammatory diseases: beyond the Th1/Th2 paradigm. Int. Immunol. 28(4), 163-171 (2016).

56. Lim, A. I., Verrier, T., Vosshenrich, C. A. \& Di Santo, J. P. Developmental options and functional plasticity of innate lymphoid cells. Curr. Opin. Immunol. 44, 61-68 (2017).

57. Grivennikov, S. I., Greten, F. R. \& Karin, M. Immunity, inflammation, and cancer. Cell 140(6), 883-899 (2010).

58. Ghoreschi, K. et al. Generation of pathogenic T(H)17 cells in the absence of TGF- $\beta$ signalling. Nature 467(7318), 967-971 (2010).

59. Santarlasci, V. et al. TGF-beta indirectly favors the development of human Th17 cells by inhibiting Th1 cells. Eur. J. Immunol. 39(1), 207-215 (2009).

60. Schwartzbaum, J. A. et al. Allergy and inflammatory transcriptome is predominantly negatively correlated with CD133 expression in glioblastoma. Neuro Oncol. 12(4), 320-327 (2010).

61. Fransson, M. et al. Up-regulation of Toll-like receptors 2, 3 and 4 in allergic rhinitis. Respir. Res. 6, 100 (2005).

62. Petroianu, A., Boson, W. L., Bale, A. E., Friedman, E. \& De Marco, L. Mutational analyses of candidate genes in human squamous cell carcinomas. Laryngoscope 109, 661-663 (1999).

63. Trellakis, S. et al. Peripheral blood neutrophil granulocytes from patients with head and neck squamous cell carcinoma functionally differ from their counterparts in healthy donors. Int. J.Immunopathol. Pharmacol. 24(3), 683-693 (2011).

\section{Acknowledgements}

Special thanks are given to all patients and involved institutions and investigators.

\section{Author contributions}

B.G.M.C.C., A.P., J.A.N.M., L.R.A., and V.R. designed the experiments; B.G.M.C.C., P.M.F.A., F.R.S., and S.C.B. carried out experiments; B.G.M.C.C., A.P., and J.A.N.M. analyzed the data and wrote the manuscript.

\section{Funding}

This work was supported by CNPq (National Council of Science and Technology), and FAPEMIG (Foundation for Research Support of Minas Gerais State).

\section{Competing interests}

The authors declare no competing interests.

\section{Additional information}

Correspondence and requests for materials should be addressed to B.G.M.C.C.

Reprints and permissions information is available at www.nature.com/reprints.

Publisher's note Springer Nature remains neutral with regard to jurisdictional claims in published maps and institutional affiliations.

(c) (1) Open Access This article is licensed under a Creative Commons Attribution 4.0 International License, which permits use, sharing, adaptation, distribution and reproduction in any medium or format, as long as you give appropriate credit to the original author(s) and the source, provide a link to the Creative Commons licence, and indicate if changes were made. The images or other third party material in this article are included in the article's Creative Commons licence, unless indicated otherwise in a credit line to the material. If material is not included in the article's Creative Commons licence and your intended use is not permitted by statutory regulation or exceeds the permitted use, you will need to obtain permission directly from the copyright holder. To view a copy of this licence, visit http://creativecommons.org/licenses/by/4.0/.

(c) The Author(s) 2021 